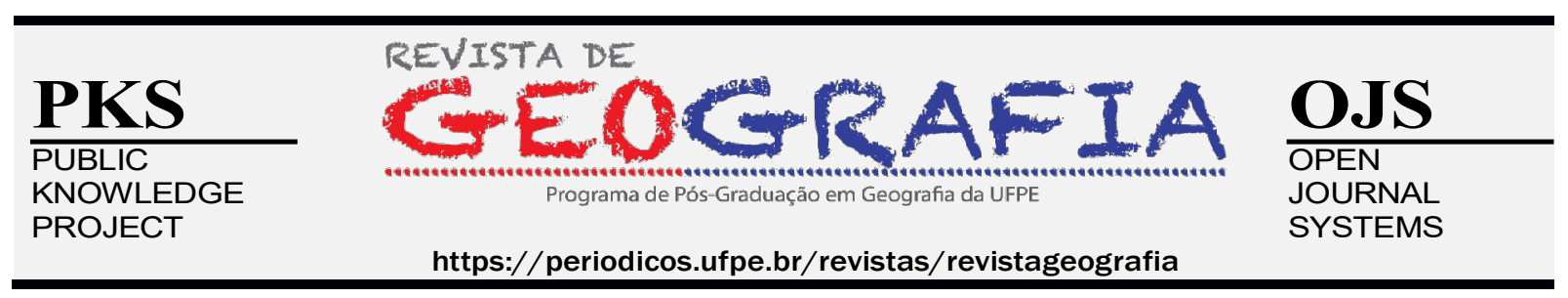

\title{
EDUCAÇÃO AMBIENTAL E ESPAÇOS DE VIVÊNCIA: A RELAÇÃO ENTRE ESCOLA, ALUNOS E MEIO AMBIENTE EM CAUCAIA-CE
}

\author{
Ana Letícia Freitas Lima ${ }^{1}$, Francisco Samuel Nobre Ramos², Edson Vicente da Silva ${ }^{3}$ \\ ${ }^{1}$ Universidade Federal do Ceará, E-mail: leticialima.geoufc@gmail.com \\ ${ }^{2}$ Universidade Federal do Ceará, E-mail: samuelnobre@alu.ufc.br \\ ${ }^{3}$ Universidade Federal do Ceará, E-mail: cacauceara@gmail.com
}

Artigo recebido em 29/12/2019 e aceito em 10/06/2020

\begin{abstract}
RESUMO
A sociedade atual está subjugada por padrões desenvolvimentistas, que degradam o meio ambiente através das ações humanas e seu padrão de consumo negligente. Assim, este trabalho pensa a escola como um espaço e instrumento valoroso para o desenvolvimento de consciência e postura críticas dos escolares. O lócus da pesquisa, foi a Escola Celina Sá Morais da rede municipal de Caucaia - CE. O principal fator motivador para a escolha desta foi sua proximidade com o mar e o intento em investigar a relação da comunidade escolar com este ambiente litorâneo. A abordagem é qualitativa, com destaque para os aspectos subjetivos que dizem respeito à percepção e às vivências dos sujeitos pesquisados. Do ponto de vista procedimental, utilizou-se de questionários e entrevistas semiestruturadas; observações sistemáticas; e análise dos documentos oficiais, nacionais e da escola, relacionados à questão ambiental, na busca de contrapor o oficial e o real. Assim, podese constatar que os sujeitos que dão corpo a escola compreendem a dinâmica e a fragilidade do ambiente em que se encontram, conseguem vislumbrar a necessidade de conservação desse meio, e reconhecem a potencialidade da localização da escola como recurso de ensino e aprendizagem, ainda que atividades e projetos não sejam desenvolvidos permanentemente.
\end{abstract}

Palavras-chave: Escola; Educação Ambiental; Ensino de Geografia; Espaços de Vivência.

\section{ENVIRONMENTAL EDUCATION AND LIVING SPACES: THE RELATIONSHIP BETWEEN SCHOOL, STUDENTS AND ENVIRONMENT IN CAUCAIA-CE}

\begin{abstract}
The current society is overwhelmed by developmental patterns, which degrade the environment through human actions and its negligent consumption pattern. Thus, this paper thinks the school as a valuable space and instrument for the development of critical awareness and posture of students. The locus of the research was the Celina Sá Morais School in Caucaia - CE. The main motivating factor for choosing this was its proximity to the sea and the intention to investigate the relationship of the school community with this coastal environment. The approach is qualitative, with emphasis on the subjective aspects that concern the perception and experiences of the research subjects. From the procedural point of view, we used questionnaires and semistructured interviews; systematic observations; and analysis of official, national and school documents related to the environmental issue, seeking to counteract the official and the real. Thus, it can be seen that the subjects who embody the school understand the dynamics and fragility of the environment in which they find themselves, can glimpse the need for conservation of this environment, and recognize the potentiality of the school's location as a teaching and learning resource, even if activities and projects are not developed permanently.
\end{abstract}

Keywords: School; Environmental education; Geography teaching; Living Spaces. 


\section{INTRODUÇÃO}

$\mathrm{O}$ modelo de sociedade em que vivemos atualmente encontra-se subjugado por padrões desenvolvimentistas, que degradam o meio ambiente por meio das ações humanas e um consumismo desenfreado e irresponsável. A integração de países e suas culturas, sofrem um processo de homogeneização através da globalização, o que é uma característica das sociedades contemporâneas. A globalização tende a promover uma proximidade virtual, encurtando as distâncias e atenuando as fronteiras, em decorrência da rapidez cada vez maior das ações e dos fluxos de informações. No entanto, ela também contribui para a apropriação de elementos culturais e estilos de vida que não são intrínsecos de determinada cultura, o global insere-se no local. Dessa forma, muitas vezes, esse global se sobrepõe fazendo com que se deixe de lado as origens, não visualizando as potencialidades e fragilidades dos espaços de vivência, voltando-se a atenção para o mundo a fora, para o que é exterior. Assim, se desconhece em parte, as raízes, as causas e os processos pelos quais os ambientes, em que o indivíduo está inserido, passam. Focando, em geral, quando isso acontece, no produto, no resultado, e em formas superficiais de resolver e/ou mitigar os problemas que surgem no final de um processo complexo.

Diante dessa realidade, concebe-se a escola como um meio para desenvolver uma consciência crítica dos estudantes com relação aos espaços de vivência e a questão ambiental. A escola não pode ficar alheia ao que acontece fora de seu espaço, antes deveria considerar os lugares de vivência como espaços também de aprendizagens.

Cada vez mais as questões ambientais são postas em evidência, a degradação da natureza tem gerado grandes preocupações, discussões e demandam ações efetivas e de conscientização das pessoas. Essas questões também chegam ao ambiente escolar, fazendo professores e alunos refletirem sobre as suas atitudes e o que pode ser feito para melhorar e contribuir para um mundo melhor. Deve ser ensinado para os alunos, que os diversos tipos de ambientes são dotados de características variadas, possuindo potencialidades e fragilidades, podendo ser susceptíveis a vulnerabilidade ou não.

A discussão das questões relacionadas ao meio ambiente, e da própria Educação Ambiental (EA), não é algo recente, é uma característica das sociedades modernas que exploram a natureza e os seus recursos até a exaustão dos sistemas naturais. A preocupação com o meio ambiente e a sua degradação tem ganhado maior destaque nos últimos anos, se 
consolidando na contemporaneidade devido, principalmente, a perda de qualidade de vida da população e da premência da conservação ambiental.

No passado, a EA, fundamentada principalmente por princípios positivistas, tinha como objetivo principal disseminar atitudes "ecologicamente" corretas, baseadas no conhecimento científico produzido. O papel da EA na perspectiva tradicional se restringia apenas a transmissão de valores que viabilizassem uma conduta ambientalmente aceitável. Romper com essas práticas, que ainda são bastante presentes e marcantes na educação brasileira, é uma preocupação pessoal e deve ser de todos os professores, a fim de contribuir de fato, com a formação de sujeitos críticos da sociedade e suas questões ambientais.

A temática desta pesquisa está relacionada com a investigação das relações existentes entre os sujeitos pesquisados, em especial, os alunos da Escola de Educação Infantil e Ensino Fundamental (EEIEF) Celina Sá Morais, e o meio em que estão inseridos, quer sejam estes os seus espaços de vivência na escola, e nas suas próprias casas, ou ainda o ambiente da praia, região onde a escola encontra-se situada e onde reside grande parte dos alunos. A escola Celina Sá Morais é uma escola de ensino infantil e fundamental da rede municipal de Caucaia no Ceará, e está localizada no bairro de Icaraí, a cerca de $200 \mathrm{~m}$ do mar.

A pesquisa teve como objetivo geral analisar as relações existentes entre estudantes, escola e meio circundante para compreender como alunos e professores se posicionam diante da questão ambiental.

\section{PERCURSOS METODOLÓGICOS}

Como supracitado, esta pesquisa foi realizada na EEIEF Celina Sá Morais, uma escola da rede pública do município de Caucaia, localizada no bairro Icaraí (Figura 1). Foram analisados os espaços, e no que tange aos sujeitos, foram pesquisadas as turmas de $8^{\circ}$ e $9^{\circ}$ anos do Ensino Fundamental, bem como a professora de Geografia responsável pelas turmas. 
Figura 1: Mapa de localização da escola no bairro de Icaraí em Caucaia

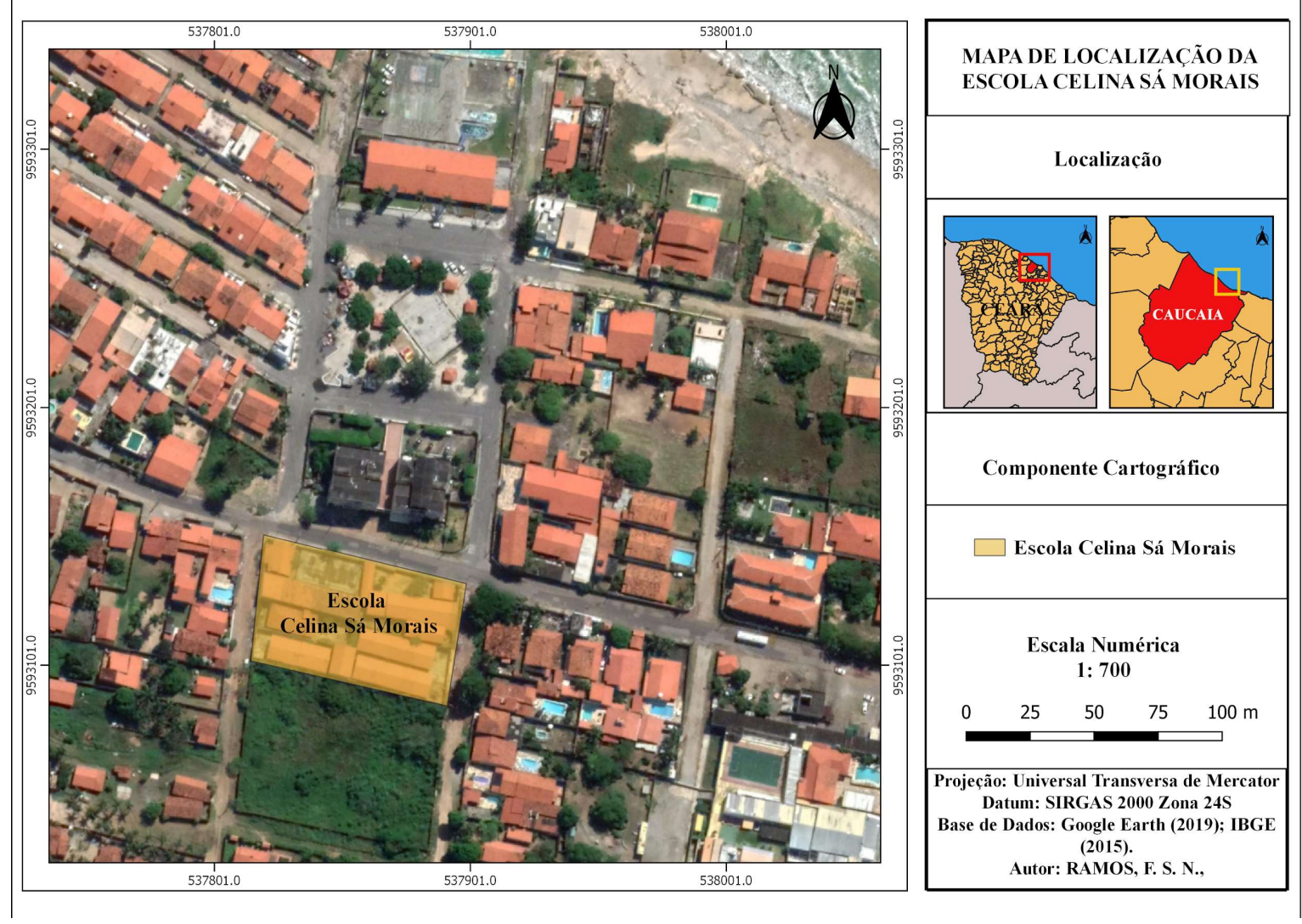

Fonte: RAMOS, F. S. N. (2019)

Trata-se de uma pesquisa com enfoque especialmente qualitativo, visto que, a partir da ótica da investigação dos sujeitos da pesquisa, alunos e professores, buscou compreender e analisar a sua subjetividade, as suas percepções sobre o meio em que vivem. Nessa compreensão,

[...] a pesquisa qualitativa integra o campo transdisciplinar, à medida que adota multimétodos de investigação, na busca de encontrar sentido para o fenômeno estudado. Assim, o pesquisador pode socializa-la com diferentes recursos linguísticos, tais como as narrativas, os relatos, as memórias, os recursos estatísticos, entre outros. (CHIZZOTTI, 2003 apud LIMA, 2012, p. 63-64).

No que tange aos objetivos da pesquisa, esta trata de uma investigação explicativa, visto que, objetiva identificar os fenômenos, analisando os fatores que contribuem ou determinam a ocorrência destes. (GIL, 2008, p. 28). Há de se ressaltar que a pesquisa explicativa é antecedida por uma descrição dos vários fatores que caracterizam o fenômeno em estudo. 
Do ponto de vista dos procedimentos, o presente trabalho se configura como uma pesquisa reflexiva, pois, trata-se de um posicionamento crítico que busca organizar a dialética dos processos que permeiam a investigação em curso. (GHEDIN; FRANCO, 2011, p. 108). Assim, esta perspectiva de pesquisa e de metodologia,

[...] organiza cientificamente todo o movimento reflexivo, do sujeito ao empírico e deste ao concreto, até a organização de novos conhecimentos, que permitam nova leitura/compreensão/interpretação do empírico inicial. (GHEDIN; FRANCO, 2011, p. 107).

Como técnicas para obter os dados e informações necessárias à pesquisa, foram aplicados questionários com os alunos das duas turmas escolhidas, $8^{\circ}$ e $9^{\circ}$ anos. Posteriormente, realizou-se entrevistas semiestruturadas com dois grupos de alunos, um de cada turma, sendo cada grupo constituído por cinco alunos, a escolha foi baseada nas respostas dadas pelos alunos às perguntas do questionário, optando por aquelas de elaboração mais complexa e que de fato buscaram responder aos questionamentos propostos. Também, realizou-se uma entrevista semiestruturada com a professora responsável pelas disciplinas de Geografia e História da escola; foram realizadas observações sistemáticas e reflexivas dos diversos espaços escolares; analisou-se ainda, os documentos oficiais nacionais, que regem a educação brasileira, a Lei de Diretrizes e Bases (LDB) e os Parâmetros Curriculares Nacionais (PCN), e os documentos oficiais da escola, o Projeto Político Pedagógico (PPP) e o Regimento Escolar. Sobre a pesquisa em contexto escolar, Lima faz algumas ponderações:

O que observar na Escola em movimento? Estamos falando de uma postura atenta, para além das paredes e demais estruturas físicas, objetos, estatísticas e documentos da instituição. É o olhar demorado sobre os fatos, nexos e relações que se estabelecem no movimento das pessoas para descobrir os fenômenos embutidos nos fatos aparentemente corriqueiros ou comuns as particularidades e detalhes do fenômeno estudado. Esse olhar poderia estar se aproximando da reflexão sobre a escola enquanto um organismo vivo com identidade própria, construída pela comunidade que a compõe em sua especificidade e diferença das demais. (LIMA, 2012, p. 61-62).

O enfoque específico da pesquisa está relacionado à relação com o ambiente, portanto, as observações destinaram-se principalmente a tentar compreender a relação dos alunos e da escola com o ambiente litorâneo no qual estão inseridos, buscando chamar a atenção dos alunos para as fragilidades do ambiente e da necessidade de conservá-lo. 
Observou-se como os professores utilizam essa situação de proximidade com o mar como recurso didático em suas aulas, buscando dinamizar as aulas e formar cidadãos críticos e conscientes.

A fim de fundamentar teoricamente a pesquisa, foi realizada uma revisão bibliográfica com as seguintes temáticas: professor pesquisador, docência, ensino de Geografia, educação ambiental, espaços de vivência, dentre outras.

\section{O QUE PRESCREVEM OS DOCUMENTOS OFICIAIS?}

\section{A Lei de Diretrizes e Bases (LDB)}

A Lei de Diretrizes e Bases da Educação Nacional (LDB) é um documento que define e regulamenta a organização da educação no Brasil embasado por princípios da Constituição brasileira. No que tange as diretrizes para a EA, a LDB não apresenta regulamentações específicas. Na verdade, em todo o texto da versão mais atual e vigente da LDB há apenas uma única menção a EA, mais especificamente no inciso que determina que: "Os currículos do ensino fundamental e médio devem incluir os princípios da proteção e defesa civil e a educação ambiental de forma integrada aos conteúdos obrigatórios." (BRASIL, 2012). Este inciso foi incluído através da Lei 12.608 de 10 de abril de 2012.

Fica subentendido, que os direcionamentos da LDB para a EA se dão no contexto da educação para a cidadania e de forma integrada as disciplinas que compõem o currículo oficial, visto que, em seu Artigo 32, determina que o ensino fundamental tenha como objetivo a formação básica do cidadão. Para isso, a educação deve ser capaz de promover "II - a compreensão do ambiente natural e social do sistema político, da tecnologia das artes e dos valores em que se fundamenta a sociedade.” (BRASIL, 1996). Seguindo a mesma linha, em outro ponto, a Lei determina que os currículos da educação básica (ensino infantil, fundamental e médio) devem abranger tais temáticas citadas anteriormente.

Ainda em nível nacional, há as propostas de Diretrizes Curriculares Nacionais para a Educação Ambiental. Este documento busca estabelecer diretrizes e orientações relacionadas à Educação Ambiental que, de acordo com as exigências legais, devem estar presentes em todos os níveis e modalidades de ensino.

Estas Diretrizes Curriculares Nacionais para a Educação Ambiental estão embasadas, em grande parte, na Lei 9.795/99 que "Dispõe sobre a educação ambiental, 
institui a Política Nacional de Educação Ambiental e dá outras providências". (BRASIL, 1999).

A Política de Educação Ambiental se mostraria bastante abrangente e satisfatória, se de fato fosse aplicada integralmente em todas as escolas e em todos os níveis. As proposições alinham-se com as propostas de uma EA Crítica e com os princípios da Complexidade Ambiental. O Artigo $4^{\mathrm{o}}$ é categórico quanto a estes pontos, em especial, no seu parágrafo segundo, onde define como princípios básicos da EA “a concepção do meio ambiente em sua totalidade, considerando a interdependência entre o meio natural, o sócioeconômico e o cultural, sob o enfoque da sustentabilidade;”. (BRASIL, 1999). Interessante também ressaltar que a Política de Educação Ambiental recomenda que a EA seja trabalhada de forma multi, inter e transdisciplinar, ou seja, de forma integrada a todas as disciplinas, não devendo ser incluída como uma disciplina específica no currículo formal.

A LDB, enquanto Lei que rege todo o sistema educacional brasileiro, em todos os níveis, não faz determinações concretas voltadas diretamente para a EA, no entanto, leis posteriores acabam por se somar a esta, complementando-a e fazendo as recomendações e delimitações mínimas necessárias para a EA na educação do país. Entretanto, ressalta-se que nem sempre tais recomendações e diretrizes são seguidas fielmente, comprometendo assim sua eficácia. O cumprimento de tais direcionamentos poderia levar a uma mudança radical nas ações voltadas para a EA que existe em nossas escolas e demais ambientes de aprendizagem, enfim, na sociedade como um todo. Poderia assim contribuir em uma possível transformação de postura e de consciência diante das questões e problemáticas ambientais vivenciadas.

\section{Os Parâmetros Curriculares Nacionais (PCN)}

Os Parâmetros Curriculares Nacionais (PCN) constituem-se em uma série de documentos que configuram recomendações básicas para a elaboração das matrizes de referência, que se trata de um conceito utilizado para descrever as habilidades que são esperadas que os alunos desenvolvam nas diferentes etapas de escolarização. Os PCN foram elaborados para propalar os princípios da reforma curricular e direcionar a busca de novas abordagens e metodologias pelos professores.

Assim como na LDB, nos PCN a Educação Ambiental encontra-se atrelada a ideia de educação para a cidadania, embora haja um texto específico com as diretrizes da EA para 
a educação básica. Estas temáticas são trazidas como Temas Transversais, que tratam de questões importantes, fazendo-se urgentes e presentes de diferentes formas, no cotidiano dos alunos e de toda a sociedade.

Os Parâmetros Curriculares Nacionais têm por objetivo nortear e padronizar a educação no Brasil, trazendo a questão da educação para a cidadania, apontando como ferramenta importante à inserção dos Temas Transversais dentro dos conteúdos das disciplinas já existentes. O texto que faz alusão a essa questão constitui-se da seguinte maneira:

O compromisso com a construção da cidadania pede necessariamente uma prática educacional voltada para a compreensão da realidade social e dos direitos e responsabilidades em relação à vida pessoal, coletiva e ambiental. Nessa perspectiva é que foram incorporadas como Temas Transversais as questões da Ética, da Pluralidade Cultural, do Meio Ambiente, da Saúde e da Orientação Sexual. (BRASIL, 1997a, p. 15).

A inserção destes temas vem contribuir com a formação de cidadãos, levando à construção e resgate de valores e a apreensão de conteúdos que visem o desenvolvimento de habilidades que permitam a atuação efetiva dos alunos na sociedade. As questões sociais devem ser apresentadas aos alunos para que estes possam compreendê-las e refletir sobre elas.

Os Temas Transversais tratam de questões predominantemente sociais, assim, difere das demais áreas do conhecimento convencionalmente conhecidas e trabalhadas, além disso, a complexidade que envolve tais temas faz com que nenhuma área isolada possa dominá-lo de forma plena, sendo necessária a interdisciplinaridade para o desenvolvimento satisfatório dos temas. Na análise desse conteúdo,

Por exemplo, a questão ambiental não é compreensível apenas a partir das contribuições da Geografia. Necessita de conhecimentos históricos, das Ciências Naturais, da Sociologia, da Demografia, da Economia, entre outros. (BRASIL, 1997a, p. 36).

Compreendendo a necessidade de uma formação cidadã e a importância da Geografia nesse processo, é interessante ressaltar a relevância de se trabalhar as questões ambientais, principalmente na escola escolhida para a realização da pesquisa. A EA é um dos caminhos que contribuem com a construção de uma formação cidadã, visto que propicia ao aluno uma tomada de conhecimento do que diz respeito à degradação e a necessidade de 
conservação e preservação do meio ambiente, despertando para práticas "ecologicamente corretas". Segundo Silva,

Predomina, na cultura brasileira, a idéia de que a função maior da educação ambiental é despertar a consciência ecológica na sociedade, sensibilizando as crianças e os jovens - as futuras gerações - para a compreensão da problemática ambiental e a importância da aquisição de novos comportamentos e atitudes. (SILVA, 2005, p. 05).

Os PCN destacam que uma das principais funções de se trabalhar o tema da questão ambiental em sala de aula é a formação de cidadãos conscientes e comprometidos com a vida. No entanto, afirma que para isso,

[...] é necessário que, mais do que informações e conceitos, a escola se proponha a trabalhar com atitudes, com formação de valores, com o ensino e a aprendizagem de habilidades e procedimentos. E esse é um grande desafio para a educação. Comportamentos "ambientalmente corretos" serão aprendidos na prática do dia-adia na escola: gestos de solidariedade, hábitos de higiene pessoal e dos diversos ambientes, participação em pequenas negociações podem ser exemplos disso. (BRASIL, 1997b, p.25).

A escola deve oferecer, ao longo de todos os anos que compõem o ensino fundamental (caso da escola pesquisada), meios diversos para que os alunos possam compreender efetivamente os fatos e os fenômenos naturais e sociais envolvidos na temática ambiental. Assim, os PCN determinam que ao final do ensino fundamental os alunos sejam capazes de se identificar como integrantes da natureza, desenvolvendo uma relação de afetividade com esta; perceber e valorizar a diversidade natural e sociocultural posicionando-se com respeito diante das diferenças; observar e analisar fatos do ponto de vista ambiental de forma crítica; adotar nos diversos espaços de vivência posturas que corroborem com interações construtivas, justas e ambientalmente sustentáveis; entender como as problemáticas ambientais interferem direta e indiretamente na qualidade de vida das pessoas; adquirir noções básicas sobre o meio ambiente; perceber as relações de causa/efeito nos fenômenos naturais condicionando a vida humana no tempo e no espaço; e, conhecer e dominar técnicas e procedimentos de conservação e manejo dos recursos naturais podendo aplicá-los na vida cotidiana. (BRASIL, 1997b, p. 197-198). O documento chama a atenção para alguns pontos importantes:

Outro ponto importante a ser considerado é a relação da escola com o ambiente em que está inserida. Por ser uma instituição social que exerce intervenção na realidade, ela deve estar conectada com as questões mais amplas da sociedade, e com os movimentos amplos de defesa da qualidade do ambiente, incorporando-os 
às suas práticas, relacionando-os aos seus objetivos. É também desejável a saída dos alunos para passeios e visitas a locais como parques, empresas, unidades de conservação, serviços públicos, lugares históricos e centros culturais, e se estabeleça um contato para fins educativos. (BRASIL, 1997b, p. 192).

Em síntese, os PCN apresentam uma proposta pedagógica para a EA que se volta mais para o desenvolvimento de atitudes e posturas éticas, e para o domínio de técnicas e procedimentos a serem aplicados no dia a dia, em detrimento de uma aprendizagem acerca de conceitos. Nesta análise, considera-se de grande importância tais propostas, entretanto, devem ser tomadas algumas precauções a fim de que não se caia na mesmice de formar sujeitos práticos que realizam inúmeras atividades até relevantes para mitigar os efeitos dos problemas ambientais, mas que não refletem sobre a sua prática e que desconhecem os processos que levaram a tal quadro de degradação do meio ambiente. Portanto, o estudo e compreensão dos conceitos relacionados à temática, atrelado aos conteúdos e atividades de caráter procedimental e atitudinal são de extrema importância para o desenvolvimento integral do aluno.

\section{Projeto Político Pedagógico da Escola (PPP)}

Foi requerido à coordenação pedagógica da escola o Projeto Político Pedagógico (PPP) da mesma, entretanto o documento não pôde ser disponibilizado para análise em decorrência deste está passando por uma reformulação e atualização. Dessa forma, é apresentada aqui uma análise da versão anterior do PPP da escola.

O PPP estabelece como proposta para a educação no município de Caucaia promover uma ruptura com o paradigma tradicional da educação. Estabelece também as necessidades de escolarização deste milênio, que seria: a democratização dos saberes e valores das diferentes culturas construídas historicamente.

A escola, de acordo com o PPP, apresenta um conselho de gestão colegiada "onde a autonomia, a participação, a construção compartilhada dos níveis de decisão e posicionamento crítico, contrapõe-se a ideia de subalternidade e do autoritarismo". Propõe a reconstrução da cultura popular e melhorar qualitativamente o modo de vida do povo.

Além disso, a gestão da escola é tida como democrática e participativa. A diretoria de gestão escolar tem a unidade escolar como um elo mediador entre a instituição de ensino e a comunidade, e essa unidade escolar seria o ponto de partida e de chegada da ação pedagógica. 
No que tange a propostas para a EA, o documento não traz nenhuma proposição. Entretanto, foi informado pela diretora e pela coordenadora pedagógica da escola que as alterações que estavam em construção no PPP dizem respeito à inclusão de propostas e especificações relacionadas com essa temática. Essas alterações visam também, atender a exigências para a continuidade de um projeto de EA, que vem sendo desenvolvido na escola em parceria com o Instituto Brasil Solidário (IBS).

\section{RELAÇÃO DOS ESCOLARES COM OS ESPAÇOS DE VIVÊNCIA}

\section{Relação dos alunos com a escola}

É na fala dos alunos e alunas que fica mais evidente a relação destes com o meio ambiente, em especial com a praia. Nas duas turmas analisadas, $8^{\circ}$ e $9^{\circ}$ ano, foram aplicados 61 questionários. Sendo posteriormente, escolhido um grupo de alunos de cada turma, mediante as respostas dadas ao questionário, para serem entrevistados. Na turma do $8^{\circ}$ ano foi entrevistado um grupo de cinco alunos, e na turma do $9^{\circ}$ ano, também cinco alunos.

A escola Celina Sá Morais localiza-se na Rua Belarmino José, no bairro Icaraí, município de Caucaia Ceará. A escola possui 50 anos de história, sendo fundada no dia 04 de agosto de 1969, através do decreto de $\mathrm{N}^{0}$ 818.173. A localização da escola, próxima a faixa de praia, foi um dos fatores que levaram a escolha da escola e do tema da pesquisa. $\mathrm{O}$ prédio da escola está situado a $200 \mathrm{~m}$ da praia, sofrendo influência direta da maritimidade, tanto natural quanto cultural.

Grande parte dos alunos matriculados na escola reside no próprio bairro onde a escola está inserida (Icaraí), ou em bairros vizinhos, muitos também localizados em áreas litorâneas. Dos 61 alunos que responderam os questionários, 50, ou cerca de 81,9\%, responderam que moram no Icaraí, sendo os demais, (11 ou 18,1\%) residentes em outros bairros, como Jardim Icaraí, Barra Nova e Pacheco.

\section{Relação dos alunos com o mar}

As perguntas presentes na entrevista, bem como no questionário aplicado preliminarmente, buscavam compreender onde esses alunos moravam; como estes se relacionavam com a sua escola e com o ambiente do entorno; qual a proximidade do bairro deles com a praia; se costumavam frequentá-la; que atividades costumavam realizar; quais 
aspectos positivos e negativos eles destacam em tais espaços; e, o que poderia ser feito para melhorá-los.

Dos cinco alunos entrevistados na turma do $9^{\circ}$ ano, três praticam surf, e apenas uma não frequentava a praia por não gostar. Três alunos moram no bairro do Icaraí, mesmo bairro onde está localizada a escola, e os outros dois moram no bairro do Pacheco, um bairro vizinho também situado no litoral.

Os outros cinco alunos entrevistados na turma do $8^{\circ}$ ano, três moram no Icaraí e dois moram em bairros mais distantes da praia, no Jardim Icaraí e na Barra Nova. A maioria dos alunos relata que costumam frequentar a praia para fins de lazer. Grande parte dos alunos entrevistados frequenta a praia do Icaraí para surfar, tomar banho, apenas para espairecer, e alguns familiares e conhecidos realizam atividade de pesca.

Os alunos das duas turmas relataram que às vezes alguns professores realizam atividades de campo na praia, a fim de fazer o recolhimento de lixo na faixa de areia. Eles reconhecem a importância dessas atividades e da consciência de preservar o meio ambiente, e gostariam que as práticas fossem realizadas com maior frequência. Em conversa com estes alunos é notável que eles reconhecem os problemas de ordem natural e antrópica que vem acometendo a praia do Icaraí, em especial o avanço do mar.

Portanto, pode-se dizer que os alunos têm a praia, em especial a do Icaraí, como um lugar, visto que o "[...] lugar é o espaço que se torna familiar ao indivíduo, é o espaço do vivido, do experienciado." (CAVALCANTI, 1998, p. 89). Tal concepção de espaço é trabalhada pela Geografia Humanística, que segundo Tuan (1982), “[...] procura um entendimento do mundo humano através do estudo das relações das pessoas com a natureza, do seu comportamento geográfico bem como dos seus sentimentos e ideias a respeito do espaço e do lugar.” (TUAN, 1982, p. 143 apud CAVALCANTI, 1998, p 89).

Conhecer e compreender o contexto social e no caso, ambiental, que estão inseridos é um grande passo para a formação de cidadãos comprometidos e preocupados com a conservação da vida e a preservação do meio em que vive e da natureza como um todo.

\section{A visão da professora de Geografia sobre os espaços de vivência e a questão ambiental}

A professora de Geografia da escola, que também ministra aulas de História, em entrevista informou que possui curso de licenciatura em Geografia pela Universidade do Vale do Acaraú (UVA), concluído no ano de 2009 no Município de Sobral - CE. Sua 
formação conta também com um curso de especialização em Educação Ambiental. Possui seis anos de trabalho docente, sendo um ano em escola profissionalizante e outro no ensino superior, ministrando as disciplinas de Física Aplicada a Geociências e Geografia Agrária, e os demais em escolas da educação básica regular.

No que diz respeito às dificuldades em sala de aula, a professora fala sobre a falta de atenção dos alunos, e a carência de acompanhamento familiar. O número excessivo de alunos em sala de aula, uma média de 40 alunos por sala, também se torna um desafio. A professora aponta ainda, o quão importante é a adoção de metodologias que visam tornar as aulas mais dinâmicas a fim de incentivar a participação dos alunos, tornando a aprendizagem mais significativa.

A docente também ressalta que os professores devem procurar compreender as vivências, a realidade e o contexto social que os alunos estão inseridos, valorizando as suas experiências. Dessa maneira, sua concepção encontra apoio nas palavras de Freire (1997):

Pensar que é possível a realização de um tal trabalho em que o contexto teórico se separa de tal modo da experiência dos educandos no seu contexto concreto só é concebível a quem julga que o ensino dos conteúdos se faz indiferentemente ao e independentemente do que os educandos já sabem de suas experiências anteriores à escola. (FREIRE, 1997, p. 65).

Outra problemática ressaltada pela docente está relacionada não só a escola em si, mas ao modelo educacional vigente como um todo, diz respeito a constatação de que este não valoriza as habilidades dos alunos, nas palavras dela "a escola é uma prisão", pois não permite o desenvolvimento pleno do educando. No entanto, quando ocorrem atividades diferenciadas, que fogem a aula tradicional expositiva, como por exemplo, as atividades do projeto de EA desenvolvidas na escola pelo IBS, nitidamente identifica-se habilidades nos alunos que no cotidiano são "silenciadas", ou seja, não se manifestam.

$\mathrm{Na}$ entrevista realizada com a professora de Geografia, ficou claro que ela reconhece a importância de trabalhar a temática da EA, principalmente fazendo uso da interdisciplinaridade. Entretanto, problemas de ordem infraestrutural e da própria organização da escola, e do sistema educacional institucionalizado, inviabilizam a realização de tais atividades. Ela relata que na escola há a possibilidade de acesso às tecnologias e outros recursos didáticos, entretanto, o tempo se configura como fator limitante em decorrência do número de alunos e dos afazeres burocráticos. 
Outro ponto destacado pela professora, diz respeito à questão do planejamento. Ela diz que as atividades relacionadas à temática da EA poderiam ser realizadas em parceria com outras disciplinas, como Ciências, por exemplo. Entretanto, os planejamentos não são realizados de forma conjunta o que também prejudica o desenvolvimento de tais atividades e acaba por comprometer a interdisciplinaridade, a qual a própria professora reconhece a importância de sua aplicação.

De acordo com o discurso da professora, a escola e os professores esforçam-se em realizar atividades diferenciadas, e que algumas vezes utilizam o espaço da praia próximo a escola para a realização dessas, exemplo disso, foram alguns trabalhos de campo realizados com o intuito de fazer a coleta de lixo da praia, chamando a atenção dos alunos para a necessidade de preservação e conservação do meio ambiente. No entanto, a própria reconhece as dificuldades intrínsecas ao processo e, acaba por não realizar com frequência tais atividades devido ao número excessivo de alunos por turma, como citado anteriormente.

Em sua concepção, uma forma de resolver ou pelo menos atenuar os problemas relacionadas à eficácia das ações pedagógicas e do próprio modelo de ensino seria viabilizar um acompanhamento mais próximo do aprendizado e desenvolvimento do aluno, através da diminuição das turmas, e no caso das práticas voltadas para a EA, criar uma disciplina voltada exclusivamente para esta temática, a exemplo do que já acontece em algumas escolas. No entanto, esta última medida vai de encontro às diretrizes da LDB que recomendam que a EA seja trabalhada de forma interdisciplinar, não sendo alocada como uma disciplina específica no currículo das instituições de ensino.

\section{CONSIDERAÇÕES FINAIS}

No mundo globalizado, com os imensuráveis avanços da ciência e da tecnologia é cada vez mais difícil que as pessoas leigas percebam a importância da natureza viabilizando tal progresso. O ser humano se coloca e se percebe como superior, visto que, é dotado de "racionalidade", e assim, essa racionalidade legitima a sua ação predatória sobre a natureza e os recursos naturais em prol de um dito "progresso" e "desenvolvimento".

Ao longo da história, sociedade e natureza se distanciaram, sendo tratados de forma dissociada, desse modo acentuou-se ainda mais o quadro de explotação e degradação do meio ambiente, visto que, a sociedade não se insere nele, não se identifica enquanto parte constituinte de um todo maior e complexo. Neste contexto, na concepção de Leff (2001, p. 
224) apud Soares; Navarrro; Ferreira (2004, p. 45-46), quando se pensa em consciência ambiental isto implica em uma busca e afirmação de novos valores na maneira como se vê e se vive no mundo, considerando nesse processo a complexidade ambiental, que permite a construção de modelos cognitivos que sejam capazes de reconhecer a interdependência e o inacabamento de toda e qualquer ação, de (des)construção e/ou (re)construção do pensamento científico, cultural e tecnológico com a finalidade de movimentar o processo criativo humano a fim de gerir novas possibilidades frente os fenômenos da vida e sobrevivência a partir da sinergia existente no tecido social, ambiental e tecnológico.

A partir disso, questiona-se essa nova forma de ver e vivenciar o Mundo, e se essa foi alcançada ou encontra-se em processo na escola pesquisada. Portanto, persiste a dúvida. Será que a concepção que se tem de EA não está equivocada? Será que esta não se encerra na ideia de realizar atividades manuais de reciclagem e reaproveitamento de resíduos sólidos, que fujam do cotidiano tradicionalista da sala de aula? Até que ponto atividades pontuais conseguem surtir efeitos duradouros e cumprir objetivos em longo prazo?

Escola e comunidade, duas esferas da sociedade tão próximas, mas ao tempo, tão distantes. A escola, muitas vezes, encontra-se aberta para a comunidade, mas esta não a frequenta como deveria por achar que a escola realiza uma função completamente distinta e isolada daquela que lhe cabe enquanto sociedade. Este estranhamento e distanciamento acabam por inviabilizar uma relação e parceria que seria bastante benéfica para ambas às partes. Isto se reflete nas ações e posturas dos alunos, produto (mas sobretudo agente) desta relação, bem como no desenvolvimento das ações pedagógicas e do seu aproveitamento, via participação e desempenho dos alunos nestas.

Para além do diálogo que não se estabelece eficazmente entre comunidade e escola, há ainda, um aproveitamento superficial das situações, fenômenos e relações que se estabelecem fora dos ambientes formais de ensino. Isso ocorre não por falta de interesse da escola, mas por uma conjuntura muito mais ampla que atinge todo (ou quase todo) o sistema educacional vigente, que diz respeito às condições infraestruturais, à condições de trabalho (docente e discente) e, à própria concepção de escola e de ensino.

Esse panorama dificulta o desenvolvimento de ações permanentes e constantes voltadas à educação para cidadania e educação ambiental. Atividades pontuais, e muitas vezes, dissociadas de um contexto interdisciplinar predominam no cotidiano escolar. O que 
acaba por fugir das recomendações e diretrizes apontadas pelos documentos oficiais que regulam a educação brasileira.

Percebe-se que, as relações que se estabelecem entre os alunos e os seus espaços de vivência, escola e o ambiente da praia, se limitam ao campo afetivo e de lazer, ainda que, esta afetividade não esteja fortemente relacionada à noção de cuidado e zelo. Por parte da escola, esta reconhece a importância e as potencialidades do ambiente em que está inserida como um recurso eficaz do ensino e aprendizagem, entretanto, não há uma apropriação efetiva.

Os questionamentos levantados e os objetivos traçados no início da pesquisa foram contemplados, visto que, foi possível compreender a relação entre os alunos, a escola e o meio ambiente como proposto no introito desta investigação. Pôde ser analisado o que é proposto, o que se efetiva na prática e escolar e o que é ansiado pela comunidade escolar no âmbito da educação ambiental, o descompasso, no entanto, é nítido. Muito há de ser planejado e viabilizado (burocraticamente) para que se atinja uma educação (EA) crítica, transformadora, capaz de formar plenamente agentes críticos e construtores de um mundo, ambientalmente e socialmente melhor e mais justo.

O desfecho da pesquisa veio reafirmar o quão importante é conhecer e compreender o contexto social e ambiental no qual escola e comunidade escolar estão inseridos para a formação de cidadãos comprometidos e preocupados com a vida e com a preservação do meio em que vivem e da natureza na sua totalidade. É com a reflexão acerca do meio, dos processos e das práticas que são realizadas que será possível uma mudança em relação às concepções de ensino, escola, EA, sustentabilidade e desenvolvimento que são correntes na sociedade atual.

\section{REFERÊNCIAS}

BRASIL. Constituição (1996). Lei no 9.394, de 20 de dezembro de 1996. Lei de Diretrizes e Bases. Brasília, 1996.

BRASIL. Constituição (1999). Lei no 9.795, de 27 de abril de 1999. Política Nacional de Educação Ambiental. Brasília, 1999. 
BRASIL. Constituição (2012). Lei no 12.608, de 10 de abril de 2012. Política Nacional de Proteção e Defesa Civil. Brasília, 2012.

BRASIL. Secretaria de Educação Fundamental. Parâmetros Curriculares Nacionais: apresentação dos temas transversais, ética. Brasília: MEC/ SEF, 1997a. 146p.

BRASIL. Secretaria de Educação Fundamental. Parâmetros Curriculares Nacionais: Meio Ambiente e Saúde. Brasília, MEC, 1997b.

CAVALCANTI, Lana de Souza. Geografia, Escola e Construção de Conhecimentos. Campinas: Papirus, 1998.

FREIRE, Paulo. Professora sim, tia não: cartas a quem ousa ensinar. São Paulo: Olho D'água, 1997.

GHEDIN, Evandro; FRANCO, Maria Amélia Santoro. Questões de método na construção da pesquisa em educação. 2. ed. São Paulo: Cortez, 2011.

LIMA, Maria Socorro Lucena. Estágio e Aprendizagem da Profissão Docente. Brasília: Liber Livro, 2012.

SILVA, Marina. Encontros e Caminhos: Formação de Educadoras(es) Ambientais e Coletivos Educadores. Brasília, Ministério do Meio Ambiente, 2005.

SOARES, Bernardo Elias Correa; NAVARRO, Marli Albuquerque; FERREIRA, Aldo Pacheco. Desenvolvimento sustentado e consciência ambiental: natureza, sociedade e racionalidade. Ciência e Cognição, Rio de Janeiro, v. 2, p.42-49, jul. 2004. 